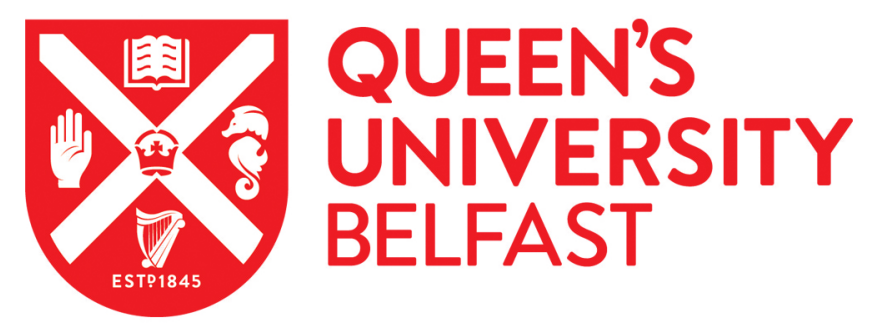

\title{
Predicting Longitudinal Changes in Familism in an Emerging Immigrant Context
}

Mejia, Y., Taylor, L. K., Stein, G. L., \& Gonzalez, L. M. (2021). Predicting Longitudinal Changes in Familism in an Emerging Immigrant Context. Journal Of Family Issues. https://doi.org/10.1177/0192513X21993205

\author{
Published in: \\ Journal Of Family Issues
}

Document Version:

Peer reviewed version

Queen's University Belfast - Research Portal:

Link to publication record in Queen's University Belfast Research Portal

Publisher rights

Copyright 2021 the Authors. This work is made available online in accordance with the publisher's policies. Please refer to any applicable terms of use of the publisher.

\section{General rights}

Copyright for the publications made accessible via the Queen's University Belfast Research Portal is retained by the author(s) and / or other copyright owners and it is a condition of accessing these publications that users recognise and abide by the legal requirements associated with these rights.

Take down policy

The Research Portal is Queen's institutional repository that provides access to Queen's research output. Every effort has been made to ensure that content in the Research Portal does not infringe any person's rights, or applicable UK laws. If you discover content in the Research Portal that you believe breaches copyright or violates any law, please contact openaccess@qub.ac.uk. 
Predicting Longitudinal Changes in Familism in an Emerging Immigrant Context

\author{
Yesenia Mejia $^{1}$ \\ Laura K. Taylor ${ }^{2}$ \\ Gabriela L. Stein ${ }^{1}$ \\ Laura M. Gonzalez ${ }^{1}$
}

1. University of North Carolina at Greensboro

2. University College Dublin; Queen's University Belfast

Correspondence concerning this article should be addressed to Yesenia Mejia, Doctoral Student in Clinical Psychology, Department of Psychology, University of North Carolina at Greensboro, 296 Eberhart Building

PO Box 26170, Greensboro, NC, 27402-6170.

Contact: ycmejia@uncg.edu, (626) 715-6905.

\title{
Acknowledgements
}

This research was supported by a New Faculty Grant awarded to Dr. Gabriela L. Stein and Dr. Laura M. Gonzalez by the University of North Carolina at Greensboro. We thank the families and schools for their time and participation in the study. The data, analytic methods, and study materials will be made available to other researchers upon request. Requests can be made to Dr. Gabriela L. Stein, glstein@uncg.edu. 
Predicting Longitudinal Changes in Familism in an Emerging Immigrant Context Familism is a core Latinx value that emphasizes deference to family and prioritizing family over the self, and is typically examined as a predictor of positive psychosocial outcomes in Latinx youth and their families (Stein et al., 2014). Few studies have examined predictors of familism in Latinx youth, with the majority of work focusing on how familism contributes to adjustment, psychopathology, and well-being (Hernández \& Bámaca, 2016). The few studies that have explored this association have found that ethnic identity (e.g., affect toward one's ethnic group, perceptions of others' views of their group) and family processes are two factors that play a significant role in predicting familism values (Carlo, White, Streit, Knight, \& Zeiders, 2017; Stein, RivasDrake, \& Camacho, 2016). This relation has been established through cross-sectional as well as longitudinal studies; however, research that has examined longitudinal associations has typically been conducted in traditional immigrant destinations (i.e., California, Kiang \& Fuligni, 2009; Arizona, Knight et al., 2014). Additionally, no studies to our knowledge have examined how familism develops or changes across time in relation to core ethnic identity processes (i.e., public and private regard) and familial experiences (i.e., familial support). How cultural and familial processes intersect with familism values may differ in emerging immigrant communities, as these communities lack the cultural resources present in established destinations (Stamps \& Bohon, 2010). This study extends past research by testing the longitudinal associations between familism values, and ethnic identity and family processes within an emerging immigrant context.

\section{Familism in Emerging Immigrant Communities}


The U.S. Latinx population has experienced significant growth over the past few decades, becoming the fastest growing ethnic group in the United States (Pew Research Center, 2017). Although Latinx communities were traditionally concentrated in locations such as California and South Florida, there has been a significant influx of Latinx immigrants choosing to settle in new destinations, such as North Carolina, Arkansas, and Georgia (Wainer, 2006). Several studies have established differences in adaptation and functioning between Latinxs living in emerging immigrant communities and those living in more established traditional destinations. For example, Latinxs in new immigrant destinations must deal with unique challenges as they navigate their new social context and assimilate into the local U.S. culture, such as changes in social and economic position, loss of family and peer networks, and segregation and discrimination at work, school, and within the broader community (Perreira, Chapman, \& Stein, 2006). Further, Latinx immigrants in new destinations are still gaining English language proficiency, and lack social and political support and advocacy, and knowledge of specific resources that typically help and benefit those living in established destinations (Stamps \& Bohon, 2006).

Studies examining various social, educational, and mental health outcomes between Latinxs living in traditional destinations and those living in new immigrant destinations have yielded mixed results. For example, Latinxs in emerging immigrant destinations tend to have higher educational attainment (Stamps \& Bohon, 2006), but evidence higher rates of depression (Shattell et al., 2009), and experience significantly more discrimination than Latinxs living in established destinations (Potochnick, Perreira, \& Fuligni, 2012). One factor that has been identified as a protective mechanism against 
negative outcomes in Latinx youth is familism (Stein et al., 2014), yet how families foster this value in different social contexts is not well understood. Some studies have identified acculturation processes (e.g., social, psychological, and cultural changes that result from balancing two cultures while adapting to the local culture) as significant predictors of familism, finding both negative and positive associations between the two. For example, youth in emerging immigrant destinations tend to have higher levels of familism, that decline gradually as they become more assimilated to U.S. culture (Smokowski, Rose, \& Bacallao, 2008). Higher acculturation has also been associated with increased familism among U.S. born Latino boys, but with decreased familism among immigrant Latino boys (Gil, Wagner, \& Vega, 2000). Given these mixed results and the unique circumstances experienced by Latinxs in emerging immigrant communities, which likely impact different aspects of acculturation, it is increasingly important to understand how protective factors such as familism values develop over time to promote positive youth development and adaptation in these at-risk communities.

\section{Family Processes and Familism}

Familism has been associated with positive family relationships, such as high family cohesiveness and connectedness, and positive parent-child relationships (Stein et al., 2014). A large literature has established the important role that families play in fostering this value through cultural socialization. For example, longitudinal examinations have found that mothers' and fathers' cultural values and their socialization practices predict cultural values in their children (Knight et al., 2011;Umaña-Taylor, Alfaro, Bámaca, \& Guimond, 2009). Other factors, such as relationship quality, have also been positively associated with greater endorsement of familism values (Carlo et al., 
2017). However, families are diverse and complex, and each provides a unique context for fostering familism; thus, it is important to continue teasing apart which family processes are key in fostering these values.

\section{Familial Support.}

Research suggests that parents who endorse familism values may demonstrate higher levels of engagement to their families and have more supportive relationships with their children (Calzada, Huang, Anicama, Fernandez, \& Brotman, 2012; White \& Roosa, 2012). Yet, research examining the specific role of family support in fostering familism is scarce. Hernández and Bámaca-Colbert (2016) proposed a conceptual model (i.e., Behavioral Process Model of Familism; BPMF) wherein parenting behaviors, such as support, warmth, and consistent discipline, serve as mechanisms that directly impact youth familism values and influence psychological adjustment. Consistent with this model, extant research has found that positive parenting and cultural socialization practices promote the development of youth ethnic and cultural values (Hughes, Watford, \& Del Toro, 2016; Calzada, Tamis-LeMonda, \& Yoshikawa, 2013). Thus, parental support, such as being attentive, and showing warmth and understanding likely promotes growth in familism values in Latinx youth. This association is likely bidirectional, but research has not examined how these two domains develop in concert across time. Additionally, this relationship has not been examined within emerging immigrant destinations, where familial support may be especially crucial.

\section{Ethnic Identity and Familism}

Ethnic identity refers to cultural values, behaviors, and attitudes typically associated with a person's culture of origin (Phinney, 1992). It is typically seen as a 
construct that develops and changes over time in relation to the individual's social context (Umaña-Taylor \& Shin, 2007). One important component of ethnic identity is ethnic regard, which has been conceptualized to involve two components: 1) private regard, referring to the degree to which an individual holds positive or negative feelings about their ethnic group, and 2) public regard, referring to the degree to which an individual believes that others hold positive or negative feelings about their ethnic group (Phinney, 1990). Ethnic regard has been identified as one of the most salient promotive factors in the literature, linking it to positive outcomes in Latinx youth (Neblett, RivasDrake, \& Umaña-Taylor, 2012); however, how it develops in concert with familism values has not been as well researched. Theoretically, the integrative model of child development predicts that identity processes foster the development of familism values (Garcia Coll et al., 1996). This model suggests that social position variables, such as ethnicity, interact with the adaptive culture (e.g., current contextual demands) to predict family values. However, other models (i.e., the bicultural acculturation model), suggest that familism and ethnic identity influence one another, and that value endorsements ultimately lead to changes in identity processes (Schwartz, Unger, Zamboanga, \& Szapocznik, 2010).

The few studies that have examined how ethnic identity processes, including private regard, and familism values relate to each other over time find mixed results. One study examining links between ethnic belonging and exploration, and familism values found that the two are positively associated, with a composite measure of ethnic belonging and exploration predicting increases in familism values over time for Asian American and Latinx teens (e.g., Kiang \& Fuligni, 2009). This same pattern was also 
evident with Latinx college students where ethnic centrality supported growth in familism values across time, but in that same analysis, familism values also predicted later growth in private regard, suggesting that these two constructs intersect and mutually influence one another's development (Stein, Rivas-Drake, \& Camacho, 2016). However, no past study to our knowledge has examined how public regard and familism values influence each other over time. Public regard may be especially important to consider in an emerging immigrant context, as these youth may have integrated how others view their group in a context that may have more hostility and fewer ingroup members. This environment would likely influence their endorsement of familism values. More positive public regard may foster growth in familism values as youth see these values as being unique to their group and potentially the reason why others view their group in a positive light. Thus, in the present study we extend this past work by taking a bidirectional approach to understand how these characteristics (e.g., private and public regard, familism) work in tandem and influence one another across development in an emerging immigrant context. Given the extant literature and theory, we expect that higher levels of Latinx youth public and private ethnic regard will foster higher familism values over time.

\section{Hypotheses}

This study examined the longitudinal association between public and private ethnic regard and familial support, and familism values in a sample of 141 Latinx $7^{\text {th }}$ $10^{\text {th }}$ graders living in a semi-rural, emerging immigrant community. Understanding these associations is essential as familism is both protective and promotive, and we believe it can potentially be enhanced by these variables. We hypothesized that public and private 
ethnic regard at Time 1 (T1) would predict greater familism values at Time 2 (T2) as found in past work (Kiang \& Fuligni, 2009). We also hypothesized that family support at T1 would predict greater familism values at T2, consistent with the BPMF.

\section{Method}

\section{Participants}

One hundred and forty-one Latinx adolescents (57.4\% female; $M$ Age $=14, S D=$ 1.29 years old at T2) in $7^{\text {th }}-10^{\text {th }}$ grades participated in this school-based study. The sample consisted of adolescents from Mexican (78\%), Latinx mixed (parents from different countries of origin; $8 \%)$, Nicaraguan (2\%), Dominican (2\%) and Salvadoran (2\%) backgrounds. Other individuals identified being from Guatemalan, Colombian, Costa Rican and Cuban backgrounds. Seventy-five of the participants were not born in the United States (40.7\%) and of those foreign-born, 54\% immigrated before age 5. Approximately $95 \%$ of the participant's parents were born in countries other than the United States.

\section{Procedure}

Participants were recruited from $7^{\text {th }}, 8^{\text {th }}, 9^{\text {th }}$ and $10^{\text {th }}$ grade classrooms from three schools in North Carolina (two middle schools and one high school) in a semi-rural emerging Latinx community. Approximately $30 \%$ of the students in each of the schools identified as Latinx. Students were recruited to participate in the study in three ways: 1) approaching parents at an open-house event at the high school;2) collecting phone numbers from the school and calling each family (most of the conversations done in Spanish); and 3) sending bilingual recruitment letters and consent forms to each child in school that were returned to the front office and collected by the research team. In total, 
191 students ( $68 \%$ of those reached; $43 \%$ of total) assented and participated in the present study at T1. At T2 (one-year later), 141 adolescents participated ( $73.82 \%$ of original sample). We found no significant differences on T1 variables between those who participated at both time points.

All survey administration was completed in the participating schools' cafeterias in the fall of 2010, during class periods determined by the principal and the teachers. The participants had the option to have an English or Spanish version of the survey. Only one student chose to take the survey in Spanish. Measures not available in Spanish were translated and back translated, and then the research team resolved discrepancies jointly. The team also encouraged participants to ask for assistance at any point during the survey and checked each questionnaire to ensure the quality of the data. The participants received a $\$ 5$ gift card for participating in the study.

\section{Measures}

Familism. The 18-item Attitudinal Familism Scale (Steidel \& Contreras, 2003) was used to assess the adolescents' beliefs and attitudes toward the family. The responses are on a 10-point Likert-type scale, ranging from strongly disagree (1) to strongly agree (10) and grouped into 4 subscales. The first subscale is familial support, which includes six items such as, "Aging parents should live with their relatives." Family interconnectedness, a second subscale, is composed of five items. A sample item is, "A person should cherish time spent with his or her relatives." A third scale, family honor, is made up of four items such as, "A person should feel ashamed if something he or she does dishonors the family name." Fourth, subjugation of self for the family consists of three items. For example, "A person should be a good person for the sake of his or her 
family." Previous research demonstrated good validity of the scale as indicated by the correlations of familism factors with acculturation, generational status, and exposure to the United States (Steidel \& Contreras, 2003). The items were averaged to represent total reported familism. Internal reliability was good in our sample at T1 $(\alpha=.90)$ and T2 $(\alpha=$ $.89)$.

Private and public regard. An adapted version of the Multidimensional Inventory of Black Identity (MIBI) was utilized to assess ethnic identity in the current study (Sellers, Smith, Shelton, Rowley, \& Chavous, 1998). The MIBI was originally created to examine racial identity with African Americans. However, the MIBI was adapted for Latinx populations and showed adequate reliability and validity in previous studies with Latinx and Asian origin adolescents (Kiang, Yip, Gonzales-Backen, Witkow, \& Fuligni, 2006; Rivas-Drake, Hughes, \& Way, 2008). The private and public regard subscales were used in the current study and demonstrated adequate reliability at T1 ( $\alpha=$ $.91)$ and $\mathrm{T} 2(\alpha=.84)$.

Family Support. The Child and Adolescent Social Support Scale (CASSS) Version 2 (designed for children from $6^{\text {th }}$ to $12^{\text {th }}$ grade) measured adolescents' perceived social support from various sources, including parents (Malecki, Demaray, Elliott, \& Nolten, 2000). Previous research with a diverse sample of students in the $6-12^{\text {th }}$ grades indicated good psychometric properties (Demaray \& Malecki, 2002). Twelve of the items measured parent support examining whether participants felt their parents were understanding, helpful, attentive, etc. An example item is, "My parents listen to me when I need to talk." Adolescents rated each item based on frequency of the events occurring 
on a 6-point Likert scale from 1 (never) to 6 (always). The parent support subscale demonstrated excellent reliability at $\mathrm{T} 1(\alpha=.98)$ and $\mathrm{T} 2(\alpha=.97)$.

\section{Data Analytic Plan}

Mplus Version 6.0 (Muthén \& Muthén, 1998-2011) was used to estimate three structural equation models (SEM). Given the research questions about bivariate changes over time, a latent difference score (LDS; McArdle \& Hamagami, 2001) approach was used. The LDS is a preferred method for analyzing longitudinal change with two time points of data compared to change scores or auto-regressive, cross-lagged models. For example, the LDS explicitly models the influence of prior status on subsequent levels of change using a latent variable; in this way, LDS models are reliable and less likely to introduce bias into model estimates (King, King, McArdle, Saxe, Doron-LaMarca \& Orazem, 2006). Moreover, using the bivariate approach, in which latent difference scores are estimated for two constructs simultaneously, allows researchers to account for individual change, while assessing multivariate change processes and time-dependencies (Grimm, An, McArdle, Zonderman, \& Resnick, 2012). That is, it assesses to what degree change in one construct influences change in another construct. In these models, fullinformation maximum likelihood was used and fit statistics were not generated because all models were saturated (i.e., all paths were estimated).

\section{Results}

The means, standard deviations, and bivariate correlations for all study variables are reported in Table 1. The three LDS models are set up in the same way: the manifest variables for each construct are allowed to correlate within each time point, a latent 
difference score for each construct is estimated, the bivariate association between the two latent difference scores is estimated. Figure 1 depicts the LDS models for public regard and familism, Figure 2 models private regard and familism, and finally Figure 3 estimates the LDS model for familial support and familism in this sample.

Regarding the primary paths of interest in Figure 1, the latent change in public regard is positively and significantly related to change in familism $(\beta=.30, p<.001)$. For each construct, youth with higher scores at $\mathrm{T} 1$ reported less change over time; that is, higher familism at T1 related to less change in familism $(\beta=-.70, p<.001)$ and higher public regard at $\mathrm{T} 1$ related to less change $(\beta=-.60, p<.001)$. Finally, the latent change in both variables was not related to the $\mathrm{T} 1$ scores on the other construct; that is, $\mathrm{T} 1$ familism did not predict change in public regard and vice versa.

Figure 2 shows the same pattern of findings in the LDS model for private regard and familism. There is a positive association between change in private regard and change in familism $(\beta=.43, p<.001)$. Earlier scores also predict less change in private regard $(\beta=-.77, p<.001)$ and familism $(\beta=-.70, p<.001)$, but have no significant links to change in the other construct.

As with the private and public regard, change in family support was positively and significantly correlated with changes in familism $(\beta=.25, p<.01)$. Moreover, the T1 values for each construct related to less change for both family support $(\beta=-.58, p<$ $.001)$ and familism $(\beta=-.74, p<.001)$. Finally, there was a cross-lagged association in which more family support at $\mathrm{T} 1$ was related to more change in familism $(\beta=.20, p<$ $.01)$. However, the alternative path from $\mathrm{T} 1$ familism to change in family support was non-significant. 
In summary, the LDS models demonstrate the bivariate associations in change over time between public and private ethnic regard, family support, and familism for Latinx adolescents in an emerging immigrant context.

\section{Discussion}

This study employed a longitudinal design to examine the associations between family support and ethnic identity processes, and familism values in an emerging immigrant destination. Youth in these communities often experience unique challenges and are at heightened risk for poor outcomes given the lack of established cultural resources and support. Thus, research examining promotive and protective factors and how to foster them in these families is critical. The results suggest that for youth in these communities, identity processes are linked with cultural value endorsement, and that as predicted by BPMF, experiences of familial support foster a greater growth in familism values across adolescence.

\section{Longitudinal Increases in Familism}

Consistent with hypotheses, we found that youth who perceived higher social support from their parents at $\mathrm{T} 1$ evidenced a significant increase in familism values at $\mathrm{T} 2$. On the contrary, familism values at $\mathrm{T} 1$ were not significantly associated with perceived social support at $\mathrm{T} 2$. These findings suggest that a supportive family environment is crucial for fostering development of familism values across time, which is consistent with the BPMF. This line of reasoning is also supported by Bronfenbrenner's (1989) ecological framework, which posits that processes occurring within the family microsystem have significant effects on youth development. Our results show that when youth perceive their parents to be understanding and attentive, it promotes the 
development of familism values which may then promote healthy family interactions and positive adaptation in Latinx youth. Future studies should continue to examine how other family processes impact the development of familism values across time and within different environments. Additionally, our results suggest that interventions aimed at promoting family support can be helpful in fostering familism values as children grow.

\section{Longitudinal Increases in Private and Public Regard}

Further, consistent with hypotheses, changes in public and private regard were both significantly positively associated with changes in familism values across time. Although past work suggests that identity processes set the stage for further endorsement of familism values overtime in adolescence (Kiang \& Fuligni, 2009), our findings suggest that ethnic identity processes and familism values evolve concurrently in an emerging immigrant context, and potentially familism values are tied to how youth perceive their own ethnic group and how they understand others' views of their group as well. Studies have found that private regard is more stable across time, whereas public regard decreases as youth get older (Hughes, Way, \& Rivas-Drake, 2011) and that youth explore, create, and recreate their ethnic identities within their family setting (Hughes et al., 2016). Further, parents' attitudes, values, and behaviors play a key role in their children's ethnic racial socialization, which helps to build their ethnic identity (Priest et al., 2014; Hughes et al., 2016). These findings suggest that ethnic identity and familism values are intertwined and develop simultaneously as children grow. Importantly, familism values were positively associated with public regard suggesting that the context of how youth perceive their group is understood influences their own internalization of values. This suggests that negative immigrant rhetoric and ethnic/racial discrimination 
may have damaging effects on youth retaining important protective cultural values that foster psychological and educational adaptation. Thus, interventions aimed at fostering the development of a positive ethnic identity can be especially helpful in promoting familism values in Latinx youth. Additionally, future studies should explore how these develop in tandem in different contexts, and examine how other variables such as, discrimination, peer group, and neighborhood/community may play a role.

\section{Developmental Considerations}

Given that participants were in the mid-adolescence stage of development it is likely that their overall identities were in a stage of transition and change. While their greater social and cognitive capabilities allow ethnic socialization to promote more advanced features of ethnic identity, such as exploration and resolution (Umaña-Taylor, Gonzales-Backen, \& Guimond, 2009), this is also a stage during which identity becomes much more multifaceted. It is possible that we may see similar patterns in younger children and see a shift in identity and values as youth enter early adulthood. This is in line with social identity theory (Tajfel \& Turner, 1986), which posits that activation of any particular social identity in any given situation elicits attitudes and values associated with that social identity that guide behavior in that situation. Thus, it is important to continue longitudinal examinations of these processes, given that adolescence is a time when peer groups become increasingly important and youth are exploring multiple roles.

\section{Future Directions and Limitations}

The present study extends past literature by shedding light on how familism values develop alongside ethnic identity (i.e., ethnic regard) and family processes (i.e., support) in an emerging immigrant Latinx community. Our study found that family 
support fosters the development of familism values over time. Additionally, we found a positive relationship between ethnic identity processes and familism values. Despite these important findings, there were some limitations of the present study. For example, our study was limited to two timepoints across a one-year period. Future research should also explore these questions across a longer time period and at different developmental time points (e.g., during early childhood and early adulthood) to better predict ethnic identity and familism value trajectories. Further, our study focused on a specific sample of Latinx families within an emerging immigrant context; thus, it is not generalizable to the wider Latinx community. Moreover, we acknowledge that other familial aspects (e.g., parenting style) can be assessed in future research, which may provide additional insights into how to best foster familism values in Latinx youth. Lastly, future work should consider other aspects of the emerging immigrant context that may affect the development of these processes, such as access to resources, neighborhood and family composition, and documentation status. 
Boyd, B. M. (2011). The familial socialization of culturally related values in Mexican American families. Journal of Marriage and Family, 73(5), 913-925.

Bronfenbrenner, U. (1989). Ecological system theories. Annals of Child Development, 6, 187-249.

Calzada, E. J., Huang, K.-Y., Anicama, C., Fernandez, Y., \& Brotman, L. M. (2012). Test of a cultural framework of parenting with Latino families of young children. Cultural Diversity and Ethnic Minority Psychology, 18(3), 285-296. https://doi.org/10.1037/a0028694

Calzada, E. J., Tamis-LeMonda, C. S., \& Yoshikawa, H. (2013). Familismo in Mexican and Dominican families from low-income, urban communities. Journal of Family Issues, 34(12), 1696-1724. https://doi.org/10.1177/0192513X12460218 Carlo, G., White, R., Streit, C., Knight, G. P., \& Zeiders, K. H. (2017). Longitudinal relations among parenting styles, prosocial behaviors, and academic outcomes in US Mexican adolescents. Child Development.

Coll, C. G., Crnic, K., Lamberty, G., Wasik, B. H., Jenkins, R., Garcia, H. V., \& McAdoo, H. P. (1996). An integrative model for the study of developmental competencies in minority $\quad$ children. Child development, 67(5), 1891-1914. Demaray, M. K., \& Malecki, C. K. (2002). The relationship between perceived social support and maladjustment for students at risk. Psychology in the Schools, 39(3), 305-316.

Gil, A. G., Wagner, E. F., \& Vega, W. A. (2000). Acculturation, familism, and alcohol use among Latino adolescent males: Longitudinal relations. Journal of Community Psychology, 28(4), 443-458. 
Grimm, K., An, Y., McArdle, J., Zonderman, A., \& Resnick, S. (2012). Recent changes leading to subsequent changes: Extensions of multivariate latent difference score models. Structural Equation Modeling, 19(2), 268-268.

Hernández, M. M., \& Bámaca-Colbert, M. Y. (2016). A behavioral process model of familism: Behavioral process model of familism. Journal of Family Theory \& Review, 8(4), 463-483. https://doi.org/10.1111/jftr.12166

"How the U.S. Hispanic Population is Changing.” Pew Research Center, Washington D.C. (April 11, 2019), https://www.pewresearch.org/fact-tank/2017/09/18/howthe-u-s-hispanic-population-is-changing/.

Hughes, D. L., Watford, J. A., \& Del Toro, J. (2016). A transactional/ecological perspective on ethnic-racial identity, socialization, and discrimination. In Advances in child development and behavior (Vol. 51, pp. 1-41). JAI.

Hughes, D., Way, N., \& Rivas-Drake, D. (2011). Stability and change in private and public ethnic regard among African American, Puerto Rican, Dominican, and Chinese American early adolescents. Journal of Research on Adolescence, 21(4), 861-870.

Kiang, L., \& Fuligni, A. J. (2009). Ethnic identity and family processes among adolescents from Latin American, Asian, and European backgrounds. Journal of Youth and Adolescence, 38(2), 228-241.

Kiang, L., Perreira, K. M., \& Fuligni, A. J. (2011). Ethnic label use in adolescents from traditional and non-traditional immigrant communities. Journal of Youth and Adolescence, 40(6), 719-729. 
Kiang, L., Yip, T., Gonzales-Backen, M., Witkow, M., \& Fuligni, A. J. (2006). Ethnic identity and the daily psychological well-being of adolescents from Mexican and Chinese backgrounds. Child development, 77(5), 1338-1350.

King, L., King, D., McArdle, J., Saxe, G., Doron-Lamarca, S., \& Orazem, R. (2006). Latent difference score approach to longitudinal trauma research. Journal of Traumatic Stress, 19(6), 771-85.

Knight, G. P., Basilio, C. D., Cham, H., Gonzales, N. A., Liu, Y., \& Umaña-Taylor, A. J. (2014). Trajectories of Mexican American and mainstream cultural values among Mexican American adolescents. Journal of Youth and Adolescence, 43(12), 20122027.

Knight, G. P., Berkel, C., Umaña-Taylor, A. J., Gonzales, N. A., Ettekal, I., Jaconis, M., \& Boyd, B. M. (2011). The familial socialization of culturally related values in Mexican American families. Journal of Marriage and Family, 73(5), 913-925. Malecki, C. K., Demaray, M. K., Elliott, S. N., \& Nolten, P. W. (2000). The child and adolescent $\quad$ social support scale. DeKalb, IL: Northern Illinois University. McArdle, J. J., \& Hamagami, F. (2001). Latent difference score structural models for linear dynamic analyses with incomplete longitudinal data. Muthén, L. K., \& Muthén, B. O. (1998-2011). Mplus User's Guide. Sixth Edition. Los Angeles, CA: Muthén \& Muthén.

Neblett, E. W., Rivas-Drake, D., \& Umaña-Taylor, A. J. (2012). The promise of racial and ethnic protective factors in promoting ethnic minority youth development. Child development perspectives, 6(3), 295-303. 
Perreira, K. M., Chapman, M. V., \& Stein, G. L. (2006). Becoming an American parent overcoming challenges and finding strength in a new immigrant Latino community. Journal of Family Issues, 27(10), 1383-1414.

Phinney, J. S. (1990). Ethnic identity in adolescents and adults: review of research. Psychological bulletin, 108(3), 499.

Phinney, J. S. (1992). The multigroup ethnic identity measure: A new scale for use with diverse $\quad$ groups. Journal of Adolescent Research, 7(2), 156-176.

Potochnick, S., Perreira, K. M., \& Fuligni, A. (2012). Fitting in: The roles of social acceptance and discrimination in shaping the daily psychological well-being of Latino youth. Social Science Quarterly, 93(1), 173-190.

Priest, N., Walton, J., White, F., Kowal, E., Baker, A., \& Paradies, Y. (2014). Understanding the complexities of ethnic-racial socialization processes for both minority and majority groups: A 30-year systematic review. International Journal of Intercultural Relations, 43, 139-155.

Rivas-Drake, D., Hughes, D., \& Way, N. (2008). A closer look at peer discrimination, ethnic identity, and psychological well-being among urban Chinese American sixth graders. Journal of Youth and Adolescence, 37(1), 12-21.

Schwartz, S. J., Unger, J. B., Zamboanga, B. L., \& Szapocznik, J. (2010). Rethinking the concept of acculturation: implications for theory and research. American Psychologist, 65(4), 237.

Sellers, R. M., Smith, M. A., Shelton, J. N., Rowley, S. A., \& Chavous, T. M. (1998). Multidimensional model of racial identity: A reconceptualization of African American racial identity. Personality and Social Psychology Review, 2(1), 18-39. 
Shattell, M. M., Villalba, J., Stokes, N., Hamilton, D., Foster, J., Petrini, R. H., ... \& Faulkner, C. (2009). Depression in Latinas residing in emerging Latino immigrant communities in the United States. Hispanic Health Care International, 7(4), 190-202. Smokowski, P. R., Rose, R., \& Bacallao, M. L. (2008). Acculturation and Latino family processes: How cultural involvement, biculturalism, and acculturation gaps influence family dynamics. Family Relations, 57(3), 295-308. Stamps, K., \& Bohon, S. A. (2006). Educational attainment in new and established Latino metropolitan destinations. Social Science Quarterly, 87(5), 1225-1240.

Steidel, A. G. L., \& Contreras, J. M. (2003). A new familism scale for use with Latino populations. Hispanic Journal of Behavioral Sciences, 25(3), 312-330.

Stein, G. L., Cupito, A. M., Mendez, J. L., Prandoni, J., Huq, N., \& Westerberg, D. (2014). $\quad$ Familism through a developmental lens. Journal of Latina/o Psychology, 2(4), 224.

Stein, G. L., Rivas-Drake, D., \& Camacho, T. C. (2016). Ethnic identity and familism among Latino college students: A test of prospective associations. Emerging Adulthood, 2167696816657234.

Tajfel, H., \& Turner, J.C. (1986). The social identity theory of intergroup behavior. In S. Worchel \& W. Austin (Eds.), Psychology of Intergroup Relations ( $2^{\text {nd }}$ ed., pp.724). Chicago: Nelson Hall.

Umaña-Taylor, A. J., \& Shin, N. (2007). An examination of ethnic identity and selfesteem with diverse populations: Exploring variation by ethnicity and geography. Cultural Diversity $\quad$ and Ethnic Minority Psychology, 13(2), 178. 
Umaña-Taylor, A. J., Alfaro, E. C., Bámaca, M. Y., \& Guimond, A. B. (2009). The central role of familial ethnic socialization in Latino adolescents' cultural orientation. Journal of $\quad$ Marriage and Family, 71(1), 46-60.

Wainer, A. (2006). The new Latino south and the challenge to public education:

strategies for educators and policymakers in emerging immigrant communities. Tomas Rivera Policy Institute.

White, R. M., \& Roosa, M. W. (2012). Neighborhood contexts, fathers, and Mexican American young adolescents' internalizing symptoms. Journal of Marriage and Family, 74(1), 152-166. 
Figure 1. Model using latent difference scores $(\Delta \mathrm{d})$ to estimate the bivariate associations between change in public ethnic regard and change in familism over two time points. Dotted lines indicate non-significant paths, ${ }^{*} p<.05, * * p<.01, * * * p<.001 .^{1}=$ Time $1,{ }^{2}=$ Time 2 .

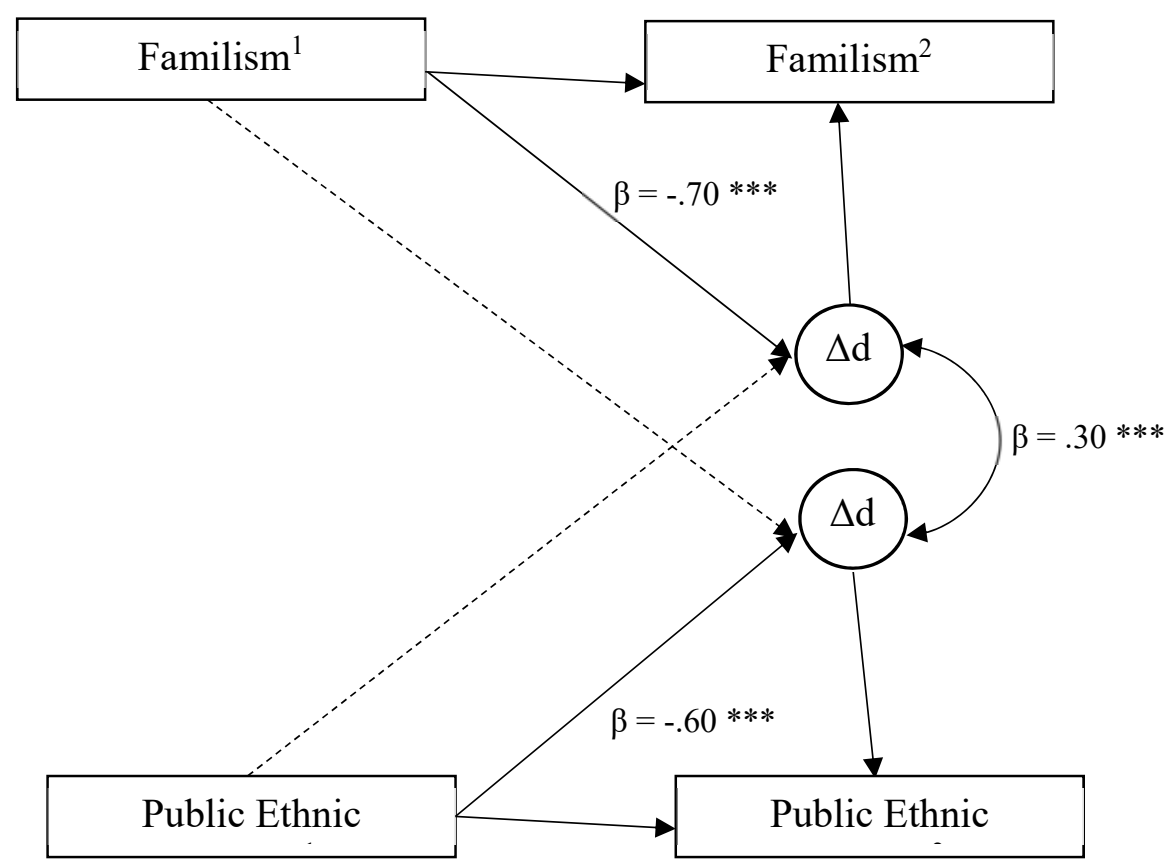


Figure 2. Model using latent difference scores $(\Delta \mathrm{d})$ to estimate the bivariate associations between change in private ethnic regard and change in familism over two time points. Dotted lines indicate non-significant paths, ${ }^{*} p<.05, * * p<.01, * * * p<.001 .^{1}=$ Time $1,{ }^{2}=$ Time 2 .

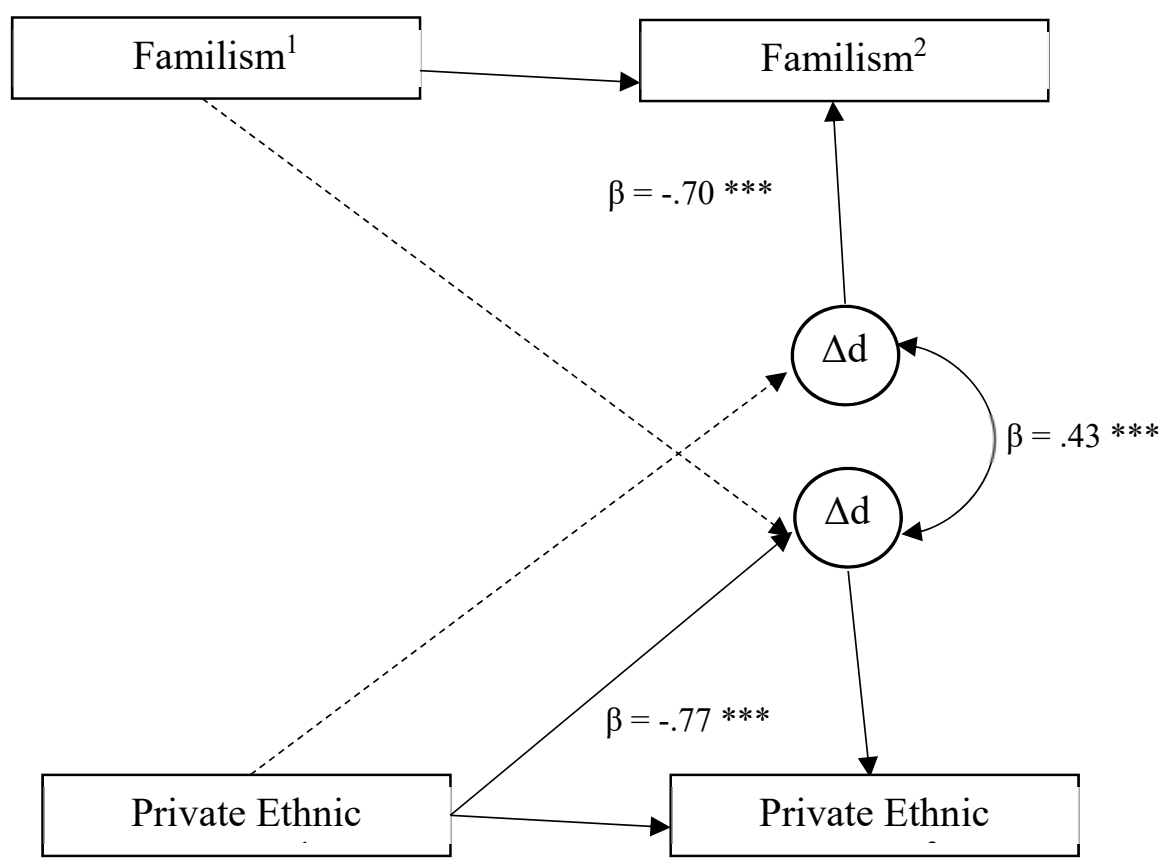


Figure 3. Model using latent difference scores $(\Delta \mathrm{d})$ to estimate the bivariate associations between change in family support and change in familism over two time points. Dotted lines indicate non-significant paths, ${ }^{*} p<.05, * * p<.01, * * * p<.001 .^{1}=$ Time $1,{ }^{2}=$ Time 2 .

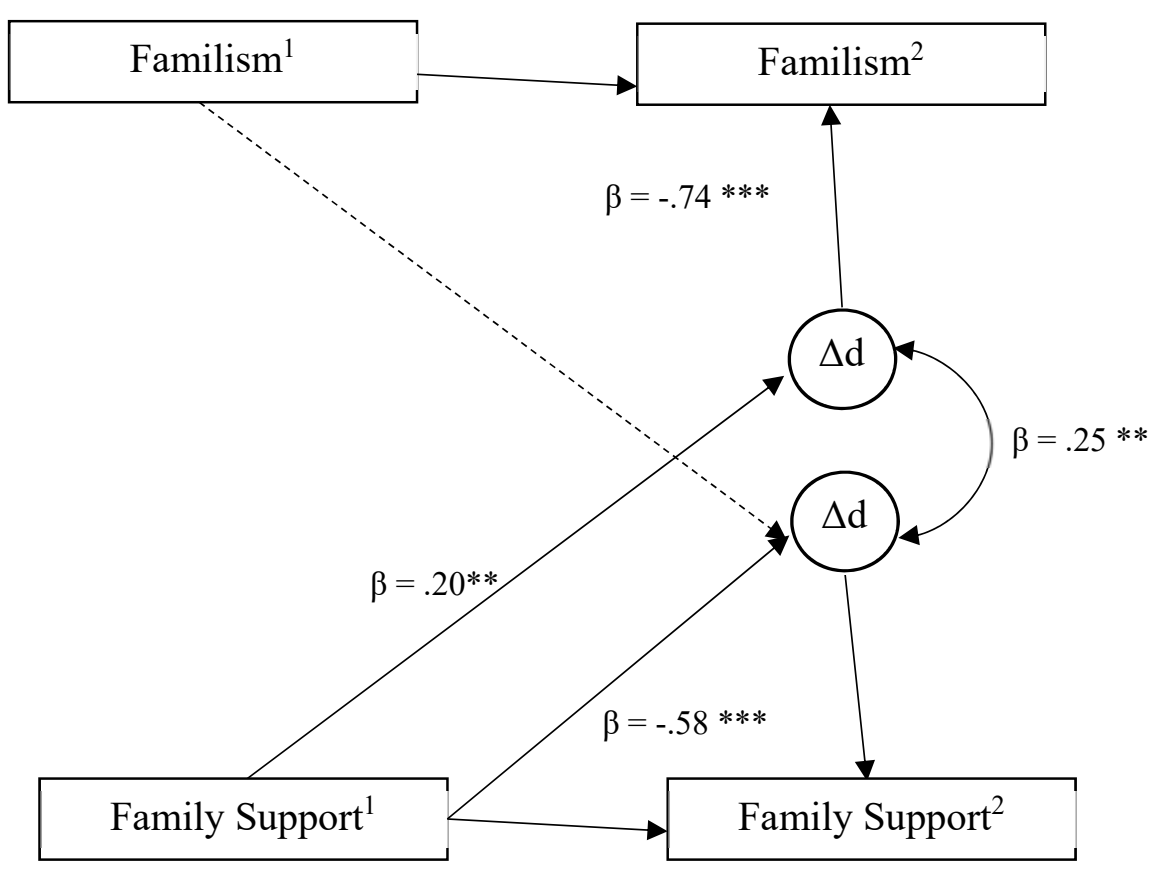


Table 1

Means, standard deviations and bivariate correlations for all study variables

\begin{tabular}{|c|c|c|c|c|c|c|c|c|c|c|c|}
\hline & & Mean & SD & 1 & 2 & 3 & 4 & 5 & 6 & 7 & 8 \\
\hline 1 & Public Ethnic Regard ${ }^{1}$ & 14.74 & 3.72 & - & & & & & & & \\
\hline 2 & Private Ethnic Regard ${ }^{1}$ & 21.74 & 4.07 & $0.53^{* *}$ & - & & & & & & \\
\hline 3 & Family Support ${ }^{1}$ & 171.31 & 30.13 & $0.25^{* *}$ & $0.23^{* *}$ & - & & & & & \\
\hline 4 & Familism $^{1}$ & 130.19 & 27.39 & $0.26^{* *}$ & $0.36^{* *}$ & $0.26^{* *}$ & - & & & & \\
\hline 5 & Public Ethnic Regard ${ }^{2}$ & 15.07 & 3.31 & $0.39^{* *}$ & -0.12 & $0.21^{*}$ & -0.01 & - & & & \\
\hline 6 & Private Ethnic Regard ${ }^{2}$ & 22.47 & 2.83 & $0.22^{* *}$ & $0.23^{* *}$ & 0.16 & 0.07 & $0.34^{* *}$ & - & & \\
\hline 7 & Family Support ${ }^{2}$ & 171.22 & 27.76 & 0.10 & 0.12 & $0.48^{* *}$ & 0.14 & $0.18^{*}$ & $0.20^{*}$ & - & \\
\hline 8 & Familism $^{2}$ & 135.84 & 22.38 & 0.11 & 0.07 & $0.33^{* *}$ & $0.33^{* *}$ & $0.26^{* *}$ & $0.40^{* *}$ & $0.37^{* *}$ & - \\
\hline
\end{tabular}

Note: $* p<.05, * * p<.01, * * * p<.001 ;{ }^{1}=$ Time $1,{ }^{2}=$ Time 2 